\title{
National stroke audit: a tool for change?
}

A G Rudd, D Lowe, P Irwin, Z Rutledge, M Pearson, on behalf of the Intercollegiate Stroke Working Party

\begin{abstract}
Objectives-To describe the standards of care for stroke patients in England, Wales and Northern Ireland and to determine the power of national audit, coupled with an active dissemination strategy to effect change.

Design-A national audit of organisational structure and retrospective case note audit, repeated within 18 months. Separate postal questionnaires were used to identify the types of change made between the first and second round and to compare the representativeness of the samples.
\end{abstract}

Setting-157 trusts (64\% of eligible trusts in England, Wales, and Northern Ireland) participated in both rounds.

Participants-5589 consecutive patients admitted with stroke between 1 January 1998 and 31 March 1998 (up to 40 per trust) and 5375 patients admitted between 1 August 1999 and 31 October 1999 (up to 40 per trust).

Audit tool-Royal College of Physicians Intercollegiate Working Party stroke audit.

Results-The proportion of patients managed on stroke units rose between the two audits from $19 \%$ to $26 \%$ with the proportion managed on general wards falling from $60 \%$ to $55 \%$ and those managed on general rehabilitation wards falling from $14 \%$ to $11 \%$. Standards of assessment, rehabilitation, and discharge planning improved equally on stroke units and general wards, but in many aspects remained poor $(41 \%$ formal cognitive assessment, $46 \%$ weighed once during admission, $67 \%$ physiotherapy assessment within 72 hours, $24 \%$ plan documented for mood disturbance, $36 \%$ carers' needs assessed separately).

Conclusions-Nationally conducted audit linked to a comprehensive dissemination programme was effective in stimulating improvements in the quality of care for patients with stroke. More patients are being managed on stroke units and multidisciplinary care is becoming more widespread. There remain, however, many areas where standards of care are low, indicating a need for investment of skills and resources to achieve acceptable levels. (Quality in Health Care 2001;10:141-151)

Fazakerley Hospital, Liverpool, UK M Pearson, consultant physician

Correspondence to: Dr A G Rudd anthony.rudd@kcl.ac.uk

Accepted 5 June 2001 elsewhere. There is good evidence that well organised care of patients with stroke reduces mortality and morbidity, with clear associations between the organisation and process of care and outcomes in terms of mortality and longer term disability. Treatments such as antiplatelet agents, thrombolysis for acute stroke, and the development of care in stroke units are well supported..$^{2}$ Meta-analysis of trials performed in stroke units have shown that these units have a number of features in common including the involvement of specialist stroke physicians and therapists, training for both qualified and unqualified staff, and regular multidisciplinary team meetings to set treatment goals for the patients. ${ }^{3}$ Components of rehabilitation have also been shown to be effective in randomised controlled trials. ${ }^{4}$

Two previous studies have shown that the quality of stroke care in the UK is poor. The Clinical Standards Advisory Group ${ }^{5}$ and the Stroke Association ${ }^{6}$ surveyed the organisation of care for stroke patients and found unacceptable variations between districts and regions. In 1997 the NHS commissioned a series of national sentinel audits which aimed to

Key messages

- Previous surveys of stroke care in the UK have identified deficiencies in the organisation and delivery of treatment.

- National audit as a strategy for improving stroke care has not previously been attempted.

- Completion of the audit cycle with an active implementation strategy between the two rounds of audit has resulted in significant improvements nationally in the delivery of treatment.

- National audit can be an effective tool for change and should be continued as part of the quality improvement process.

- There is still considerable scope to improve the quality of stroke care which remains poor in many areas.

What this paper adds to the subject The first national sentinel audit of stroke in England, Wales and Northern Ireland showed standards of organisation and provision of care to be low in many areas. Completing the audit cycle after 18 months provided an opportunity to evaluate changes in stroke care and to determine the benefits of national audit. Improvement was seen in most of the standards measured. The audit process with national benchmarking and a comprehensive dissemination programme was important in effecting change in many trusts. 


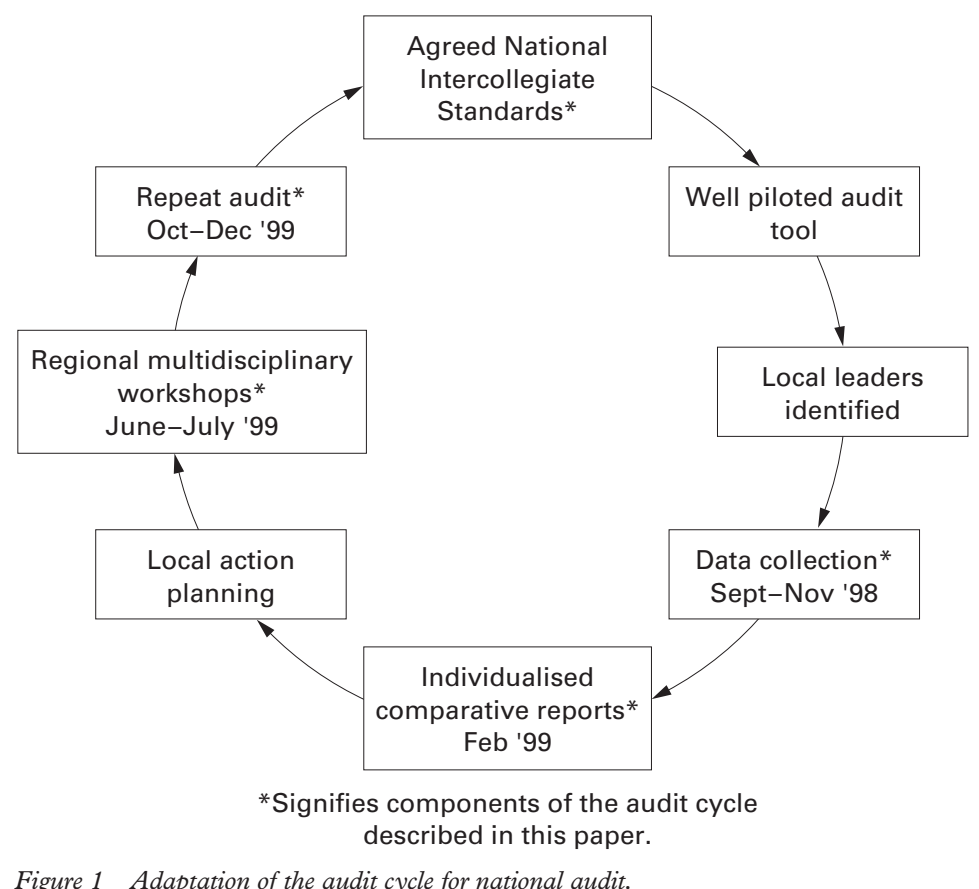

Figure 1 Adaptation of the audit cycle for national audit.

"develop clinical audit as a tool to improve the quality of care, to demonstrate multidisciplinary, cross-sectoral methods and to enable clinicians locally to improve care in accordance with nationally agreed standards". The Intercollegiate Stroke Working Party at the Royal College of Physicians developed an audit tool using evidence and consensus based standards to evaluate both the organisation of stroke care at the level of the hospital and the process of care for individuals during their passage through the health and social service system in hospital and during the first 6 months after discharge..$^{7-9}$

The national sentinel audit of stroke consisted of two rounds. The first round in 1998 showed that only $18 \%$ of the sample spent more than $50 \%$ of their hospital stay on a stroke unit, even though $50 \%$ of trusts had such a unit. ${ }^{10}$ Documented standards of care were poor in some areas-for example, only $44 \%$ of patients had visual fields recorded, $40 \%$ had been weighed during their hospital stay, and aspirin was provided following cerebral infarction in $88 \%$ of cases. Unexplained regional variations in the organisation and outcome of care were also found. ${ }^{11}$ For example, institutionalisation rates after stroke varied between $10 \%$ in North Thames and $27 \%$ in the North West region.

National audit as a tool to effect change in clinical practice has not so far been shown to be effective. What evidence there is for the benefits of audit suggests that, to have an effect, it needs to be combined with an active implementation strategy including educational outreach using local opinion leaders and providing feedback on the audit. ${ }^{12}{ }^{13}$ This paper describes the implementation and dissemination strategy following the first national audit of stroke care in 1998. The results of the first audit are compared with the second round conducted in 1999 and the reasons for the observed changes are investigated.

The key objectives of the study were to describe the changes between the two audits conducted in 1998 and 1999 and to determine the power of national audit, coupled with a dissemination strategy, to stimulate positive changes in stroke care.

\section{Methods}

The audit loop which identifies those components presented in this paper is shown in fig 1 .

SAMPLING AND DATA COLLECTION

All trusts in England, Wales, and Northern Ireland were invited to participate in the audit through a letter to the Chief Executive. They were asked to identify a lead clinician and clinical audit coordinator to be responsible for the audit locally. Auditors were trust staff of any discipline involved in the management of stroke or from the clinical audit department.

An organisational audit describing the services available within the trust was completed in each audit round. The process audit included the first 40 cases admitted during a 3 month time frame (between 1 January and 31 March 1998 and between 1 August and 31 October 1999). The first audit included 6 month follow up data about care provided in the community after discharge and therefore data were collected in October 1998. For funding reasons the second audit did not include 6 month follow up data and therefore trusts submitted data in December 1999.

\section{AUDIT TOOL}

The audit tool was developed at the Royal College of Physicians Clinical Effectiveness and Evaluation Unit under the guidance of the Intercollegiate Stroke Working Party. ${ }^{14}$ It was based on standards for service organisation and care agreed by the different professional colleges and patients' organisations represented. The standards were confirmed by a formal consensus Delphi survey ${ }^{15}$ of 90 individual experts in stroke and 10 patients' organisations external to the Working Party. The audit proformas were piloted in 14 volunteer trusts including teaching, district general and community rehabilitation hospitals, and in two general practices. Detailed explanatory notes were developed to help in the completion of the audit proformas by different members of the multidisciplinary team. Some examples of the audit standards and the explanatory notes for both the organisational audit and the process audit are given in appendix 1. Examples of the audit questions are provided in appendix 2 . To enable data to be scanned the questionnaire was designed in conjunction with optical mark recognition software (Teleform) which works with the SPSS statistical package.

The audit covered organisation and facilities for treating stroke (table 1), processes of care (table 2), and case mix and outcome of admitted patients. ${ }^{8}$ Organisational factors which had been identified by the Cochrane reviewers as being important to the success of stroke care ${ }^{3}$ such as staff expertise, team meetings, staff 
Table 1 Organisational audit domains

- Coordination of care

- Interdisciplinary services

- Staff knowledge and skills

- Team working (four aspects)

- Clinical audit (first audit only)

- Communication with patients and carers

Table 2 Process audit domains

Initial assessment

- Clinical diagnosis

- Functional assessment and screening

- Multidisciplinary involvement

- Management planning

- Continence management

- Secondary prevention

- Information giving

- Discharge planning

- Discharge planning

- Communication with carers

- Follow up and review (first audit only)

training, and involvement of carers formed the basis of the organisational audit. Case mix measures were included to help identify systematic differences between participating trusts in the types of patients treated that might explain differences in the organisation or process of care. Measures included premorbid disability as assessed by the Barthel score, age, and stroke type. Outcome measures included 7 and 30 day mortality, length of hospital stay, accommodation before and after discharge, and Barthel score on discharge.

For each process question the auditor was asked to identify whether the standard had been met or whether predefined characteristics about the patient meant that the standard was not applicable, in which case the response was "No, but ..."-for example, if patients were unconscious they could not be assessed for speech problems. An inter-rater reliability study during the first audit round showed moderate to good agreement between auditors of varying disciplines. ${ }^{9}$

First round of audit

Details of the first round of the audit conducted in 1998 have been described previously. ${ }^{10}{ }^{11}$ The Chief Executives and lead clinicians for all trusts treating patients with acute stroke in England, Wales, and Northern Ireland were invited to participate in the audit, providing data on the organisation of stroke services and a retrospective analysis of the notes of up to 40 patients admitted with stroke to the trust during the previous 6 months. 197 trusts ( $80 \%$ of all trusts) participated, reporting data on 6894 patients. Results for each trust were returned within 3 months of data submission, benchmarked against the national averages.

Confidential reports showing individual trust data benchmarked against national averages were sent to the participating trusts after each audit. In both rounds the audit results were returned to the lead clinician and the audit department in participating trusts within 3 months of data being submitted. Regional Directors of Public Health received a report showing regional variations in care and outcome, and publication of the national picture $^{10}$ after the first audit provoked considerable media interest both in the lay press and the journals of professions allied to medicine.

Following the first audit round a series of 17 multidisciplinary workshops was held around the country. Between 50 and 100 clinicians attended each meeting, in all cases including representatives from the medical, nursing, and therapy professions. At these the main messages from the national and regional findings were presented, followed by local presentations on action taken since the audit. Breakout groups were also held to discuss key issues in changing practice-for example, development of a specialist stroke service, involvement of patients in the design of services, improving documentation, use of standardised assessment measures, sharing specialist skills-to stimulate discussion among local clinicians about possible strategies for implementing change.

The principal changes being implemented were as follows:

- Care in stroke units was being broadened to develop comprehensive coordinated stroke services from one-stop clinics for transient ischaemic attacks to support and follow up in the community. Many were using specialist nurse coordinators to effect these changes.

- Many centres were developing multidisciplinary records and integrated care pathways. There was consensus that collaboration at a regional level would have been beneficial as individual hospitals were spending a lot of time developing their own systems.

- There was a widespread view that a range of agreed assessment measures would be useful and that, to allow comparisons, some national guidance on this would be helpful.

- The need for sharing skills between professionals working with stroke patients was forming the basis for staff training in some units-for example, screening for swallowing disorders should be performed by nurses and doctors (with appropriate training) for appropriate referral to speech and language therapists for in-depth assessment.

To identify the reasons for changes between the first and second round, a questionnaire asking about changes in the organisation of stroke care, staffing levels, documentation of care, and systems introduced to enhance information provision was sent to trusts shortly before the second round (box 1). Information was sought as to whether changes had occurred as a result of the audit.

\section{Second round of audit}

The methodology for the second round of the audit conducted in 1999 was identical to that used for the first round, except for adaptation of the questionnaire to remove the requirement for 6 month follow up data and the inclusion of some questions within the organisational audit form to establish staffing levels provided for stroke care within the trust sites.

In a separate questionnaire conducted after the second round, trusts were asked for their 
- Changes in stroke unit

- New unit

- Change in size

- Stroke team

- Changes in specialist staff

- Physician

- Nurse

- Stroke coordinator

- Changes in staff for stroke rehabilitation

- Physiotherapy

- Occupational therapy

- Speech and language therapy

- Psychology

- Therapy assistants

- Changes in documentation

- Care pathways

- Multidisciplinary documentation

- Agreed methods for improving documentation

- Agreed methods for better social work involvement

- Information for patients and relatives

Box 1 Domains covered in questionnaire on changes in care of stroke patients.

views as to how much more or less representative of all eligible cases their sample was in the second round compared with the first. Since data collection in the second audit was done only 6 weeks after the last admission, some cases admitted during the audit time frame might still be in hospital. If trusts coded their cases some weeks after discharge, then this could impact on patient identification as well as gaining access to notes when patients attended outpatients or visited other departments.

DATA ANALYSIS

The intention was to describe changes in the organisation and processes of care. Relevant data came from trusts taking part in both national audits of 1998 and 1999 and from the supplementary questionnaires. Changes in regional stroke unit provision were also described. In addition, the extent of selection bias was explored by comparing the results with those of the first audit and by comparing the results of the supplementary questionnaire on changes between trusts that participated and those that did not participate in the second round.

The presentation of the results is primarily descriptive through the use of tables and percentages. The percentage change in results between audits for different subsets of clinical standards is presented as median (range). Inferential methods of analysis such as tests of significance and confidence intervals to compare the results of the two audits are of limited value for the organisational audits as these come close to being a census of the organisation of care of all trusts in England, Wales, and Northern Ireland. Such methods are of more relevance to the process audits, given the differences in intake of stroke patients by sites over time, since audit patients represent a much lower proportion of all stroke patients admitted to all trusts during the period of data collection. The confidence intervals in table 4 present a range of plausible differences in results between audits, but they remain unadjusted for these (unknown) sampling fractions.

\section{Results}

AUDIT SAMPLE

A total of 197 trusts took part in the first round of the audit and, of these, 157 (64\% of eligible trusts in England, Wales and Northern Ireland in 1999) submitted data for both audits -5589 cases in 1998 and 5375 cases in 1999. The results from the 1998 audit have been reported previously..$^{10}$ Some of these data are repeated here to provide the baseline from which to interpret the data from the 1999 audit.

COMPARISON OF TRUSTS PARTICIPATING IN THE FIRST OR BOTH ROUNDS OF THE AUDIT

A comparative analysis of first round results was performed to see if there was any suggestion of selection bias in those volunteering a second time; the analysis indicated that this was not a significant issue. The 40 trusts that did not participate in the second round had a similar case mix and level of performance in their first round to the 157 trusts participating in both rounds.

The two groups of trusts had categorical results similar to within $3 \%$ with respect to sex, age category, mortality within 7 and 30 days, Barthel score category before stroke and after discharge, accommodation before stroke and after discharge, length of stay, and whether more than $50 \%$ of a patient's stay was in a stroke unit, a rehabilitation unit, or in a general ward. Information for organisational domains (table 1) enabled domain scores and a composite score to be computed. The mean domain scores for the two groups were similar, as were the mean (SD) composite scores for trusts participating in both rounds (62 (17)) and for those participating only in the first round $(67(15))$. Three quarters $(n=53)$ of compliance rates to the 71 process standards were within $5 \%$ of one another, with $63 \%$ $(n=45)$ being within $3 \%$. Trusts taking part in both audits tended to have lower compliance rates for clinical diagnosis $(9 \%, 10 \%, 11 \%$ lower for the three standards relating to likely site of cerebral lesion, type of lesion, and whether a brain scan was performed within 24 hours); for whether the patient became the responsibility of a multidisciplinary team of clinicians specialising in stroke (11\% lower), and for whether the GP was informed by the day of discharge or by the day following death (13\% lower). On the other hand, these trusts tended to have higher compliance rates in some aspects of management planning (9\% higher for agreement of rehabilitation goals by multidisciplinary team, 16\% higher for evaluation of patients progress on target dates for the team rehabilitation meeting).

ORGANISATIONAL AUDIT RESULTS FOR PARTICIPANTS IN BOTH ROUNDS Of the 38 standards measured, 29 had improved between the 1998 and 1999 audits (range 1-20\%, median 5\%). Seven standards had deteriorated, mainly in the areas of 
Table 3 Selected items from the organisational audit for the 157 trusts participating in both audits

\begin{tabular}{|c|c|c|c|c|}
\hline \multirow[b]{3}{*}{ Standard } & \multicolumn{4}{|c|}{ Compliance with standard } \\
\hline & \multicolumn{2}{|c|}{1998 ( $n=164$ sites) } & \multicolumn{2}{|c|}{1999 ( $n=157$ sites $)$} \\
\hline & Sites & $\%$ & Sites & $\%$ \\
\hline Specialist team for stroke & 75 & 46 & 89 & 57 \\
\hline Consultant with responsibility for stroke & 104 & 63 & 116 & 74 \\
\hline Agreed assessment measures for conscious level & 108 & 66 & 135 & 86 \\
\hline Agreed assessment measures for motor impairment & 61 & 37 & 84 & 54 \\
\hline Agreed assessment measures for cognitive function & 106 & 65 & 127 & 81 \\
\hline Established links with patient carer organisations & 70 & 43 & 89 & 57 \\
\hline Community user group & 97 & 59 & 104 & 66 \\
\hline Specialist continence advice available on all wards & 111 & 68 & 115 & 73 \\
\hline \multicolumn{5}{|l|}{ Specialist nursing advice on pressure care available } \\
\hline on all wards & 124 & 76 & 130 & 83 \\
\hline Practice guidelines on swallowing on all wards & 90 & 55 & 91 & 58 \\
\hline Social worker attends team meetings on all wards & 37 & 23 & 39 & 25 \\
\hline In house education programme for qualified staff & 53 & 32 & 65 & 41 \\
\hline Single set of notes for all professions & 25 & 15 & 39 & 25 \\
\hline Team meetings at least every 2 weeks on all wards & 37 & 23 & 37 & 24 \\
\hline
\end{tabular}

There was some variation in the number of sites per trust between audits and this explains the slight difference in denominators.

Median change for all 38 organisational audit items: $+2 \%$.

Median change for selected items in table $3:+10 \%$.

provision for staff knowledge and skills for the various therapies (occupational therapy, physiotherapy, and speech and language therapy), availability of guidelines on care of pressure area, access to psychiatric services, and social worker support. Two had remained unchanged. The area where change was most frequently seen was in the introduction of formal assessment measures and improvements in the use of multidisciplinary records. The results for the 14 items considered by the authors to be of greatest interest to practising clinicians are shown in table 3.

PROCESS AUDIT RESULTS FOR PARTICIPANTS IN BOTH ROUNDS

Of the 71 standards measured, 64 had improved (range between trusts 1-20\%, median $8 \%$ ) with two remaining unchanged and five deteriorating (range 1-20\%, median 4\%). For the main domains covering acute assessment and care, rehabilitation, secondary prevention, and discharge planning, improvements were evident between 1998 and 1999. The results for the 23 items considered by the authors to be of greatest clinical interest are shown in table 4. Standards for assessment, rehabilitation, and discharge planning improved equally on stroke units and general wards, but in many aspects remained poor (41\% formal cognitive assessment, $46 \%$ weighed once during admission, $67 \%$ physiotherapy assessment within 72 hours, $24 \%$ plan documented for mood disturbance, $36 \%$ carers' needs assessed separately). In the 1999 audit, as in the 1998 audit, ${ }^{10}$ compliance with the standards was significantly more likely if the patients were managed on a stroke unit than in alternative settings. For example, between 1998 and 1999 the overall proportion of patients screened for dysphagia increased from $54 \%$ to $66 \%$. For patients managed on a stroke unit the increase was from $67 \%$ to $79 \%$, while in those managed on general or rehabilitation wards only $61 \%$ were being screened by 1999. Failure to identify patients with swallowing problems puts them at risk of aspiration pneumonia which is one of the commonest causes of death following stroke. The proportion of people having a brain scan where there were clear clinical indications that this was required urgently rose from $56 \%$ to $68 \%$ on stroke units and from $48 \%$ to $61 \%$ in other ward settings between the two audits. Adequate quality of care would require near to $100 \%$ compliance with all these standards.

REASONS FOR CHANGE

Table 5 lists the changes in service organisation that had occurred between the two cycles of

Table 4 Selected measures of the process of care (\% compliance with standard)

\begin{tabular}{|c|c|c|c|c|c|c|c|}
\hline \multirow[b]{3}{*}{ Standard } & \multicolumn{4}{|c|}{$50 \%$ of stay in stroke unit } & \multicolumn{2}{|l|}{ All cases } & \multirow{3}{*}{$\begin{array}{l}95 \% \text { CI for } \\
\text { change in \% } \\
\text { compliance }\end{array}$} \\
\hline & \multicolumn{2}{|l|}{1998} & \multicolumn{2}{|l|}{1999} & \multirow[b]{2}{*}{$\begin{array}{l}1998 \\
(n=5589)\end{array}$} & \multirow[b]{2}{*}{$\begin{array}{l}1999 \\
(n=5375)\end{array}$} & \\
\hline & $\begin{array}{l}\text { Yes } \\
(n=1014)\end{array}$ & $\begin{array}{l}\text { No } \\
(n=4438)\end{array}$ & $\begin{array}{l}\text { Yes } \\
(n=1371)\end{array}$ & $\begin{array}{l}\text { No } \\
(n=4004)\end{array}$ & & & \\
\hline Conscious level recorded & $991(87 \%)$ & $4393(88 \%)$ & $1342(94 \%)$ & $3881(91 \%)$ & $88 \%$ & $92 \%$ & 3.2 to 5.5 \\
\hline Eye movements recorded & $979(74 \%)$ & $4359(67 \%)$ & $1312(86 \%)$ & $3845(74 \%)$ & $68 \%$ & $77 \%$ & 7.4 to 10.8 \\
\hline Screening for swallowing disorders & $912(67 \%)$ & $3465(51 \%)$ & $1199(79 \%)$ & $2872(61 \%)$ & $54 \%$ & $66 \%$ & 9.9 to 14.0 \\
\hline Formal mental test & $882(34 \%)$ & $3355(21 \%)$ & $997(53 \%)$ & $2331(35 \%)$ & $23 \%$ & $41 \%$ & 15.1 to 19.3 \\
\hline Assessment of visual fields & $898(58 \%)$ & $3372(40 \%)$ & $1042(75 \%)$ & $2410(57 \%)$ & $44 \%$ & $63 \%$ & 16.5 to 20.9 \\
\hline Assessment of visual inattention & $875(50 \%)$ & $3354(31 \%)$ & $1043(66 \%)$ & $2401(46 \%)$ & $35 \%$ & $53 \%$ & 15.6 to 20.0 \\
\hline Sensory testing & $900(60 \%)$ & $3383(47 \%)$ & $1055(80 \%)$ & $2437(67 \%)$ & $50 \%$ & $71 \%$ & 19.0 to 23.2 \\
\hline Brain scan carried out within 24 hours where appropriate & $529(56 \%)$ & $2513(48 \%)$ & $769(68 \%)$ & $2125(61 \%)$ & $49 \%$ & $63 \%$ & 11.2 to 16.2 \\
\hline Patient weighed once during admission & $939(58 \%)$ & $3409(35 \%)$ & $1265(61 \%)$ & $2979(39 \%)$ & $40 \%$ & $46 \%$ & 4.0 to 8.1 \\
\hline Assessment of nutritional needs & $777(80 \%)$ & $2893(66 \%)$ & $1043(89 \%)$ & $2431(77 \%)$ & $69 \%$ & $81 \%$ & 10.1 to 14.0 \\
\hline Assessment of patients mood & $934(60 \%)$ & $3329(41 \%)$ & $1230(60 \%)$ & $2872(47 \%)$ & $45 \%$ & $51 \%$ & 3.8 to 8.0 \\
\hline Physiotherapy assessment within 72 hours & $967(66 \%)$ & $3762(54 \%)$ & $1255(76 \%)$ & $2973(63 \%)$ & $56 \%$ & $67 \%$ & 8.6 to 12.6 \\
\hline Agreed rehabilitation goals & $837(74 \%)$ & $2343(50 \%)$ & $1119(77 \%)$ & $2381(50 \%)$ & $56 \%$ & $59 \%$ & 0.1 to 4.9 \\
\hline Plan for mood disturbance & $569(32 \%)$ & $2441(16 \%)$ & $663(32 \%)$ & $1619(20 \%)$ & $19 \%$ & $24 \%$ & 2.7 to 7.1 \\
\hline Management plan to promote urinary continence & $438(63 \%)$ & $1649(42 \%)$ & $426(68 \%)$ & $979(52 \%)$ & $46 \%$ & $57 \%$ & 7.3 to 13.9 \\
\hline Treatment plan for treatment of hypertension & $301(86 \%)$ & $1009(78 \%)$ & $460(88 \%)$ & $1011(81 \%)$ & $80 \%$ & $83 \%$ & 0.1 to 6.7 \\
\hline Aspirin prescribed for secondary prevention of infarction & $683(91 \%)$ & $2232(87 \%)$ & $982(92 \%)$ & $2154(89 \%)$ & $88 \%$ & $90 \%$ & 0.05 to 3.6 \\
\hline Diagnosis and prognosis discussed with patient & $810(62 \%)$ & $2666(47 \%)$ & $1233(82 \%)$ & $2952(76 \%)$ & $51 \%$ & $78 \%$ & 25.0 to 29.1 \\
\hline Post-stroke complication discussed & $792(44 \%)$ & $2600(29 \%)$ & $1189(61 \%)$ & $2671(50 \%)$ & $32 \%$ & $54 \%$ & 19.5 to 23.9 \\
\hline Discharge planning discussed & $800(78 \%)$ & $2641(64 \%)$ & $1147(86 \%)$ & $2567(80 \%)$ & $67 \%$ & $82 \%$ & 12.9 to 16.8 \\
\hline Home visit performed & $568(82 \%)$ & $1455(60 \%)$ & $611(85 \%)$ & $943(66 \%)$ & $66 \%$ & $74 \%$ & 4.8 to 10.8 \\
\hline GP informed of discharge/death within 1 day of discharge & $1002(62 \%)$ & $4329(52 \%)$ & $1252(64 \%)$ & $3679(59 \%)$ & $54 \%$ & $60 \%$ & 4.7 to 8.5 \\
\hline Carers' needs assessed separately & $705(43 \%)$ & $2829(28 \%)$ & $930(39 \%)$ & $2192(34 \%)$ & $31 \%$ & $36 \%$ & 3.3 to 7.7 \\
\hline
\end{tabular}

Results are shown for those trusts that took part in both audits. The table gives the number of cases for whom each standard was applicable and the percentage of these cases for whom the standard was met.

Median change for all 71 process audit items: $+5 \%$

Median change for selected items in table $4:+11 \%$. 
Table 5 Changes in service organisation for 157 trusts participating in both audits: results of change questionnaire

\begin{tabular}{llll}
\hline & \multicolumn{2}{l}{ Number of trusts with } \\
\cline { 2 - 4 } & $\begin{array}{l}\text { Increase (as a } \\
\text { result of audit) }\end{array}$ & No change & Decrease \\
\hline New stroke unit & $31(8)$ & 125 & 1 \\
Increase in size of stroke unit & $13(6)$ & 141 & 3 \\
Stroke team & $21(10)$ & 135 & 1 \\
Consultant stroke physician & $30(10)$ & 127 & 0 \\
Specialist nurse for stroke & $24(10)$ & 131 & 2 \\
Stroke coordinator & $16(2)$ & 135 & 6 \\
Physiotherapists & $30(6)$ & 121 & 6 \\
Occupational therapist & $28(5)$ & 124 & 5 \\
Speech and language therapist & $16(5)$ & 130 & 11 \\
Clinical psychologist & $17(2)$ & 134 & 6 \\
Interdisciplinary care pathways & $56(30)$ & 101 & 0 \\
Multidisciplinary documentation & $68(39)$ & 89 & 0 \\
Better social worker involvement & $21(15)$ & 128 & 8 \\
Information for patients and relatives & $86(52)$ & 71 & 0 \\
\hline
\end{tabular}

Table 6 Regional variations in stroke unit care

\begin{tabular}{|c|c|c|c|c|}
\hline \multirow[b]{2}{*}{ Standard } & \multicolumn{2}{|c|}{$1998(n=5587)$} & \multicolumn{2}{|c|}{$1999(n=5375)$} \\
\hline & $n(\%)$ & $\begin{array}{l}\text { Regional } \\
\text { variation }\end{array}$ & $n(\%)$ & $\begin{array}{l}\text { Regional } \\
\text { variation }\end{array}$ \\
\hline Over $50 \%$ stay on a stroke unit & $1014(19)$ & $10-37 \%$ & $1371(26)$ & $16 \%-52 \%$ \\
\hline Over $50 \%$ stay on rehabilitation unit & $784(14)$ & $5-19 \%$ & $591(11)$ & $4 \%-23 \%$ \\
\hline Over $50 \%$ stay on general ward & $3301(60)$ & $44-73 \%$ & $2926(55)$ & $40 \%-69 \%$ \\
\hline
\end{tabular}

audit, indicating how many of these changes had occurred as a direct result of the audit process. The most frequently cited initiatives that had resulted from the audit process were changes in documentation (30 trusts introducing interdisciplinary care pathways and 39 using multidisciplinary notes) and information provision (52 trusts improving their services). Among the trusts participating in the audit, 31 new stroke units had opened, eight of which were considered to have occurred as a result of participating in the audit process. The response rate to this supplementary questionnaire was $100 \%$ for those trusts who participated in both rounds.

The extent of selection bias was explored by comparing responses to this questionnaire between trusts that participated in the second audit round and those that did not. These results also suggest that selection bias was not a significant factor. Of those 40 trusts that did not participate in the second round, 27 responded and reported improvements including: new stroke unit in four (two as a result of first audit), stroke team started in four (two as a result of first audit), specialist nurse for stroke in five (two as a result of first audit), interdisciplinary care pathways in eight (four as a result of first audit), multidisciplinary documentation in 10 (five as a result of first audit), better social work involvement in four (two as a result of first audit), and improved information for patients and relatives in eight (six as a result of first audit). There were very few instances of negative change.

\section{SAMPLE REPRESENTATIVENESS}

In response to the later questionnaire about the representativeness of the sample (response rate $94 \%$ of trusts participating in both rounds), 75 of $148(50 \%)$ stated that their patient sample was "about the same" in both rounds, 27 $(18 \%)$ felt it was "more representative", 36
(24\%) "less representative", and 10 did not know. The overall neutrality of these results adds greater confidence to the validity of the comparisons made between the two audits.

\section{REGIONAL VARIATIONS IN STROKE UNIT} PROVISION

Results showing major regional variations in relation to stroke unit provision are given in table 6 . The proportion managed for more than $50 \%$ of their stay on a stroke unit in 1998 ranged from $10 \%$ to $37 \%$ (overall $19 \%$ ). In 1999 this figure ranged from $16 \%$ to $52 \%$. All the 10 regions studied increased the proportion managed in stroke units and in eight the proportion managed on general wards also fell. In six regions much of the increase in care in the stroke unit appeared to be at the cost of care on general rehabilitation units, with the proportion being managed on such units falling by as much as $12 \%$.

\section{Discussion}

The main findings of this study are that the standards of care for patients with stroke in England, Wales, and Northern Ireland have improved in nearly all of the domains audited between 1998 and 1999. However, it has highlighted many areas where considerable changes are still needed. It has shown that national audit, when combined with an active implementation strategy, can be a powerful force for change.

\section{THE AUDIT PROCESS}

This is the first large scale national audit of stroke in the UK to complete the audit cycle. It involved a large proportion of hospitals providing care for patients with stroke in England, Wales, and Northern Ireland and covered service organisation and aspects of care including acute management, rehabilitation, secondary prevention, and discharge planning.

For an audit tool to be of value it needs to be reliable, sensitive to change, feasible to complete, and acceptable to the clinicians involved. The audit tool used here was extensively piloted during the development phase. An inter-rater reliability study showed that this exercise improved data quality to levels as good as any of the large published audit studies. ${ }^{9}$ The tool was able to detect a series of improvements in both the organisation and the process of care, consistent with the findings in the change questionnaire. It would therefore seem to be sensitive to change. The audit tool does appear to identify poorly performing units and centres of excellence and therefore may be used to direct guidance for service development and clinical governance.

The case note audit was feasible to complete but was reported by clinicians participating in the regional workshops on the audit to be time consuming, taking at least 30 minutes per case. With each trust being asked to complete up to 40 cases, this was clearly a significant burden. There was a need to consult the notes of several professionals including, for the 1998 audit, obtaining information from GPs about care provided for the 6 months after discharge. The 
audit was also cross-sectoral, involving both health and social services. An alternative to this form of wide ranging audit would be to identify those audit items that were most discriminating of good and bad units and to produce a shortened version. While this would provide information needed for clinical governance, it would reduce the value of the audit to local clinicians wanting a comprehensive description of their services to be able to have clear direction as to the areas most in need of change. Using electronic patient records to automatically collect data for audit prospectively is the obvious development that needs to be made, but the technology available has not yet been shown to be feasible on a large scale. The audit received broad support from the clinicians who took part, and many instances were reported of the audit results providing the ammunition needed to stimulate change. The high proportion of trusts voluntarily participating in the second round also suggests that it was considered to be of value.

STANDARDS OF CARE

While not all the developments in stroke care observed between the two audits can be attributed to the audit, the results of the change questionnaire suggest that it was a significant factor in many cases. Thirty one new stroke units had opened in the 18 months between the audits and the proportion of patients receiving most of their treatment on a stroke unit rose from $19 \%$ to $26 \%$ in trusts participating in both audits. The organisational audit indicated that an extra 12 consultants had specific responsibility for stroke (table 3). The use of interdisciplinary care pathways and multidisciplinary documentation had increased significantly, often as a direct result of the audit. The standards of care, as measured by the audit, are considerably better for patients on stroke units than in other settings including generic rehabilitation units. ${ }^{10}$ The single most important feature of stroke care must remain the continuing development of stroke units of sufficient size to enable virtually all patients to receive the benefit. Although standards of care off stroke units are worse, it is nevertheless encouraging that improvements of a similar magnitude to those seen on the stroke units were observed between the two audits.

USING AUDIT TO EFFECT CHANGE

Encouraging change to occur requires effective dissemination and feedback of results. Trusts indicated that the confidential report detailing their performance against the national benchmark was valuable. Similarly, feedback from the 17 regional workshops between the audit rounds suggested that they were a stimulating arena for sharing ideas on good practice at a local level. Requests from participants for these to be repeated after the second round were acceded to as an important means of promulgating the recently published national clinical guidelines. ${ }^{16}$ We cannot prove that change would not have occurred with feedback of results alone, but we believe that regional workshops were an important additional factor in giving local clinicians new ideas for change and the confidence to promote those ideas.

USING GUIDELINES TO EFFECT CHANGE

The King's Fund first produced stroke guidelines, ${ }^{17}$ with more recent contributions from the Scottish Intercollegiate Guidelines Network ${ }^{18-21}$ and the Royal College of Physicians of Edinburgh consensus conferences on medical management of stroke. ${ }^{22}$ The Royal College of Physicians of London published the national clinical guidelines for stroke in $2000,{ }^{16}$ providing an overview of the evidence base linking the process of care with outcome. Extracts from the guidelines are given in box 2 to illustrate some of the key recommendations and format of the document. Development of the guidelines was carried out in parallel with the audit. They were, however, not published until after completion of the second cycle of the audit and would therefore not have been directly responsible for changes in service provision found in this audit. The impact of the introduction of the national guidelines will be

\section{Organisation of stroke care}

Every organisation involved in the care of stroke patients over the first 6 months should ensure that stroke patients are the responsibility of and are seen by services specialising in stroke and rehabilitation (A).

\section{Carers and families}

Families should be given information on the nature of stroke and its manifestations and on relevant local and national services (A), and patients and carers should be involved in decisions $(\mathbf{C})$.

\section{Diagnosis}

Brain imaging should be undertaken in all patients within 48 hours unless there are good clinical reasons for not doing so $(\mathbf{C})$.

\section{Acute treatment}

Aspirin $(300 \mathrm{mg}$ ) should be given as soon as possible after the onset of stroke symptoms (if a diagnosis of haemorrhage is considered unlikely) (A).

\section{Secondary prevention}

All patients not on anticoagulation should be taking aspirin (50-300 mg) daily (A) or a combination of low dose aspirin and dipyridamole modified release (MR). Where patients are aspirin intolerant an alternative antiplatelet agent (clopidogrel $75 \mathrm{mg}$ daily or dipyridamole MR $200 \mathrm{mg}$ twice daily) should be used (A).

\section{Rehabilitation}

CORE PRINCIPLES

Any of the current exercise therapies should be practised within a neurological framework to improve patient function (A).

MANAGEMENT

Goal setting should involve the patient (B), and family if appropriate (C).

Box 2 Examples of recommendations from the national clinical guidelines for stroke (2000). 
explored in association with future cycles of national audit.

Stroke care in the UK is improving but there is evidence that outcomes are worse than in other countries in Europe, both in mortality and morbidity. ${ }^{23}$ Continuing to improve the process of care, particularly by increasing the proportion of patients managed on specialist stroke units, must become a top priority. Solving the problem of the major regional variations in the standards and outcomes of care is also fundamental in overcoming the perception that health care in the UK is second rate.

In conclusion, comparative national audit does appear to have a positive effect by informing and cajoling healthcare providers into modifying entrenched and outdated systems of care. Further national comparative data collection has the potential to drive improvements in care, especially if linked to clinical governance, the National Service Frameworks, and the modernisation agenda. Measurement of processes of care that research has shown are linked to outcome is the only realistic way of assessing the effectiveness of individual clinical services. Few hospitals will have sufficient patients to enable valid measurement of outcome, particularly with a disease such as stroke that is as variable in its pathology and clinical presentation. Investment in process audit therefore seems justifiable.

Thanks are due to the many people who completed the audit forms to such a high standard. We are grateful to Marks and Spencer and the Stroke Association for funding the development and piloting of the audit tool and the Department of Health for funding the National Sentinel Audit.

1 Bonita R. Epidemiology of stroke. Lancet 1992;339:342-4.

2 Langhorne P, O'Williams BO, Gilchrist W, et al. Do stroke units save lives? Lancet 1993;342:395-8.

3 Stroke Unit Trialists' Collaboration. Organised inpatient (stroke unit) care for stroke (Cochrane Review). In: The (stroke unit) care for stroke (Cochrane Review). In: The
Cochrane Library, Issue 3. Oxford: Update Software, 1999. 4 Ottenbacher KJ, Jannell S. The results of clinical trials in stroke rehabilitation research. Arch Neurol 1993;50:37-44. 5 Clinical Standards Advisory Group. Report on clinical effectiveness using stroke care as an example. London: Stationery Office, 1998

6 Ebrahim S, Redfern J. Stroke care-a matter of chance: a national survey of stroke services. The Stroke Association, 1999.

7 Irwin P, Rutledge Z, Rudd A. The feasibility of a national audit of stroke. Br $\mathcal{F}$ Clin Governance 2001;6:27-33.

8 Irwin P, Rudd AG. Case mix and process indicators of outcome in stroke. F R Coll Physicians 1998;32:442-4.

9 Gompertz P, Irwin P, Morris R, et al. Reliability and validity of the intercollegiate stroke audit package. $\mathcal{F}$ Eval Clin Pract 2001; 7:1-11.
10 Rudd AG, Irwin P, Rutledge Z, et al. The national sentinel audit of stroke: a tool for raising standards of care. $\mathcal{f} R$ Coll Physicians 1999;30:460-4.

11 Rudd AG, Irwin P, Rutledge Z, et al. Regional variations in stroke care in England, Wales and Northern Ireland. Results from the national sentinel audit of stroke. Clin Rehabil 2001 (in press).

12 NHS Centre for Reviews and Dissemination. Getting evidence into practice. Effective Health Care 1999;5:1-16.

13 Pruce D, Aggarwal R. National clinical audits. A handbook for good practice. London: Royal College of Physicians, 2000.

14 Intercollegiate Stroke Working Party. Stroke audit package. London: Royal College of Physicians, 2001.

15 Turoff $M$. The design of a policy Delphi. Technological Forecasting and Social Change 1970;2:149-71.

16 Intercollegiate Working Party for Stroke. National clinical guidelines for stroke. London: Royal College of Physicians, 2000 .

17 King's Fund. Consensus statement BMF 1988;297:126-8.

18 Scottish Intercollegiate Guidelines Network (SIGN). Management of patients with stroke: I. Assessment, investigation, immediate management and secondary prevention. Edinburgh: Scottish Intercollegiate Guidelines Network, 1997.

19 Scottish Intercollegiate Guidelines Network (SIGN). Management of patients with stroke: II. Management of carotid stenosis and carotid endarterectomy. Publication No. 14. Edinburgh: Scottish Intercollegiate Guidelines Network, 1997.

20 Scottish Intercollegiate Guidelines Network (SIGN). Management of patients with stroke: III. Identification and manageagement of patients with stroke: III. Identification and manage-
ment of dysphagia. Publication No. 20. Edinburgh: Scottish Intercollegiate Guidelines Network, 1997.

21 Scottish Intercollegiate Guidelines Network (SIGN). Management of patients with stroke: IV. Rehabilitation, prevention and management of complications, and discharge planning. Publication No. 24. Edinburgh: Scottish Intercollegiate Guidelines Network, 1998.

22 Royal College of Physicians of Edinburgh. Consensus conference on medical management of stroke. Age Ageing 1998;27:665-6.

23 Wolfe CD, Tilling K, Beech R, et al. Variations in case fatality and dependency from stroke in western and central Europe. The European BIOMED Study of Stroke Care Group. Stroke 1999;30:350-6.

24 Stroke Unit Trialists Collaboration. Collaborative systematic review of the randomised trials of organised inpatien (stroke unit) care after stroke. BMF 1997;314:1151-9.

25 Royal College of Speech \& Language Therapy (RCSLT). Communicating quality: professional standards for speech and language therapists. London: RCSLT, 1996.

26 Association of Chartered Physiotherapists interested in Neurology (ACPIN). Standards of physiotherapy practice in neurology. London: CSP, 1995.

27 National Association of Neurological Occupational Therapists. Guidelines for occupational therapy for patients with neurological deficit. London: College of Occupational Therapists, 1996.

28 Redfern S. Individualised patient care: a framework for guidelines. Nurs Times 1996;92:33-6.

29 Waters KR. Getting dressed in the early morning: styles of staff/patient interaction on rehabilitation hospital wards for elderly people. 7 Advanced Nurs 1994;19:239-48.

30 Smithard DG, O'Neill PA, Park C, et al. Complications and outcome after acute stroke: does dysphagia matter? Stroke 1996;27:1200-4.

31 Smithard DG, O'Neill PA, Park C. Can bedside assessment wholly exclude aspiration following acute stroke? Age Ageing 1998;27:99-102.

32 Horner J, Massey MD, Riski JE, et al. Aspiration following stroke: clinical correlates and outcome. Neurology 1988;38: 1359-62.

33 Warlow CP, Dennis MS, van Gijn J, et al. Stroke: a practical guide to management. Oxford: Blackwell Science, 1996. 
Appendix 1: Examples of organisational and process audit standards

\begin{tabular}{|c|c|c|c|c|}
\hline Question no & Standard & Rationale & Help notes & $\begin{array}{l}\text { Where } \\
\text { most likely } \\
\text { documented }\end{array}$ \\
\hline \multicolumn{5}{|c|}{$\begin{array}{l}\text { (A) Examples of organisational audit standards with help notes } \\
\text { Staff knowledge/skills }\end{array}$} \\
\hline 1.8 & $\begin{array}{l}\text { Expertise: Patients' management } \\
\text { and care is planned and provided } \\
\text { by professionals with expertise in } \\
\text { the management of stroke } \\
\text { (a) Medical treatment } \\
\text { (b) Nursing care } \\
\text { (c) Occupational therapy } \\
\text { (d) Physiotherapy } \\
\text { (e) Speech/language therapy }\end{array}$ & $\begin{array}{l}\text { Research evidence demonstrates the importance of } \\
\text { medicine and nursing with specialist interest and } \\
\text { knowledge of stroke (A) }{ }^{24} \\
\text { Recommendations of the professional colleges. }{ }^{25-27}\end{array}$ & $\begin{array}{l}\text { Medicine: a physician with special interest in stroke } \\
\text { manages or provides advice on the management of } \\
\text { stroke patients. } \\
\text { Nursing: the system of nursing facilitates the } \\
\text { involvement of qualified nurses (with } \\
\text { postgraduate/registration education in stroke } \\
\text { rehabilitation) in direct patient care. }{ }^{28} 29 \\
\text { Occupational therapy: the occupational therapy } \\
\text { stroke service is under the overall supervision of a } \\
\text { senior occupational therapist with at least } 5 \text { years } \\
\text { experience, of which at least } 3 \text { is in neurology. }{ }^{27} \\
\text { Physiotherapy: senior physiotherapist experienced in } \\
\text { stroke rehabilitation or with access to specialist } \\
\text { supervision. }{ }^{26} \\
\text { Speech \& language therapy: specialist in acquired } \\
\text { neurological communication and swallowing } \\
\text { difficulties or with access to specialist supervision. }{ }^{25}\end{array}$ & \\
\hline \multicolumn{5}{|c|}{ Communication with patients and carers } \\
\hline 1.17 & $\begin{array}{l}\text { The organisation of the } \\
\text { ward/unit ensures that patients } \\
\text { and carers have access to their } \\
\text { management plan. }\end{array}$ & $\begin{array}{l}\text { So the patient/carer can understand the } \\
\text { rehabilitation/treatment plan and participate } \\
\text { actively in its achievement. Research suggests that } \\
\text { the involvement of carers in the rehabilitation } \\
\text { process may be a significant factor in clinical } \\
\text { outcomes from rehabilitation. (A) } .^{24}\end{array}$ & $\begin{array}{l}\text { The management plan is kept near the patient's bed } \\
\text { (e.g. at the end of the bed) where she/he and the } \\
\text { carer can refer to it. }\end{array}$ & \\
\hline \multirow{2}{*}{\multicolumn{5}{|c|}{$\begin{array}{l}\text { (B) Examples of process audit standards with help notes } \\
2.1 \quad \text { Initial assessment }\end{array}$}} \\
\hline & & & & \\
\hline $2.1 .1 \mathrm{~b}$ i) & $\begin{array}{l}\text { Full neurological assessment (cont): } \\
\text { Patients are routinely screened } \\
\text { with a standardised screening } \\
\text { procedure to check for } \\
\text { dysphagia. }\end{array}$ & $\begin{array}{l}\text { The ability to swallow should be assessed within } \\
24 \text { hours of admission. Difficulties may be } \\
\text { temporary but carry increased risk of } \\
\text { complications }(\mathbf{B}) .^{30} 31\end{array}$ & $\begin{array}{l}\text { Refers to a formal swallow screen (performed by any } \\
\text { member of the team). Presence or absence of the } \\
\text { gag reflex is not sufficient as it is proven to be of } \\
\text { little prognostic value for the ability to swallow. }{ }^{32} \\
\text { (Cf 2.2.1 for speech therapy assessment) }\end{array}$ & $\begin{array}{l}\text { Team, } \\
\text { medical or } \\
\text { nursing } \\
\text { records }\end{array}$ \\
\hline 2.1 .3 & $\begin{array}{l}\text { A brain scan is carried out within } \\
24 \text { hours where cerebral or } \\
\text { subarachnoid haemorrhage is } \\
\text { suspected, or if a patient is on } \\
\text { warfarin, or if anticoagulation or } \\
\text { thrombolysis is considered. }\end{array}$ & $\begin{array}{l}\text { Haemorrhage is visible on CT scan immediately. } \\
\text { Patients with haemorrhage may need surgical } \\
\text { intervention. Imaging is also used to exclude } \\
\text { haemorrhage before starting thrombolysis, aspirin, } \\
\text { or anticoagulation }(\mathbf{B}) .^{33}\end{array}$ & $\begin{array}{l}\text { Notes mention suspected haemorrhage and CT or } \\
\text { MRI scan. NB This refers only to emergency } \\
\text { scanning and is relevant only in the cases where } \\
\text { haemorrhage is suspected in the first } 24 \text { hours } \\
\text { after stroke. Where haemorrhage is not suspected } \\
\text { the answer will be "No but ..." }\end{array}$ & $\begin{array}{l}\text { Team or } \\
\text { medical } \\
\text { records }\end{array}$ \\
\hline 3 & Management plan & & & \\
\hline 3.1 & $\begin{array}{l}\text { There is written evidence of } \\
\text { rehabilitation goals agreed by the } \\
\text { multidisciplinary team. }\end{array}$ & $\begin{array}{l}\text { Team goals (both short and longer term) promote } \\
\text { forward planning and provide the framework for } \\
\text { coordinated multidisciplinary care. If realistic, they } \\
\text { can also help to motivate the patient. (C) }\end{array}$ & $\begin{array}{l}\text { This refers to the team goals for each patient ie not } \\
\text { those of individual disciplines. Auditors should } \\
\text { identify with their clinicians how these would be } \\
\text { documented within their trust. Where it is } \\
\text { documented that the team plan is palliative care } \\
\text { answer "No but ..." }\end{array}$ & $\begin{array}{l}\text { Team, } \\
\text { medical, } \\
\text { nursing or } \\
\text { therapy } \\
\text { notes }\end{array}$ \\
\hline
\end{tabular}


Appendix 2: Examples of organisational audit, case mix, and process audit questions (multidisciplinary involvement)

\section{(A) ORGANISATIONAL AUDIT}

Interdisciplinary services

1.5 Is there a consultant physician with specialist knowledge of Stroke who is formally recognised as having principal responsibility for stroke services?

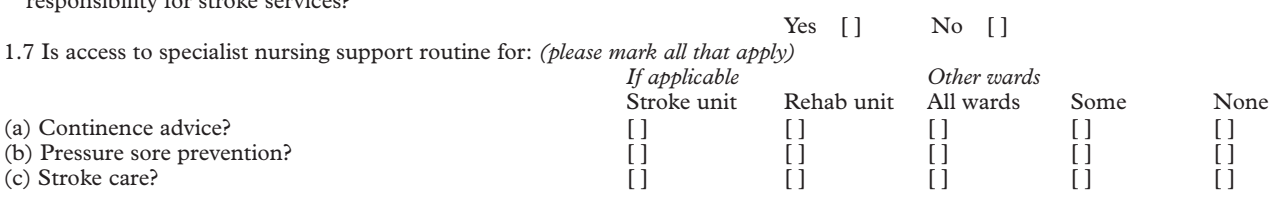

Team working

$\frac{\text { Records }}{1.11 \text { a Do all professions contribute to a single set of patient notes for the management of stroke? }}$

(please mark all that apply)

If applicable Other wards

Stroke unit Rehab unit All wards Some None

[]

[] []

[] []

$1.11 \mathrm{~b}$ Are profession-specific notes normally accessible by all members of the multidisciplinary team responsible for the patient? (please mark all that apply)

[]

[]

[]

[]

Communication with patients and carers

1.19 Is there patient information literature displayed in unit/ward on the following?

(please mark all that apply)

(a) Condition specific literature on stroke

(b) Patient versions of national or local guidelines/standards

(c) Social services local community care arrangements

(d) The Benefits Agency

(e) Local voluntary agencies

(f) How to feed back on services

$\begin{array}{ll}\text { [] } & {[]} \\ {[]} & {[]} \\ {[]} & {[]} \\ {[]} & {[]} \\ {[]} & {[]} \\ {[]} & {[]}\end{array}$

[]
[]
[]
[]
[]
[]

$\begin{array}{ll}{[]} & {[]} \\ {[]} & {[]} \\ {[]} & {[]} \\ {[]} & {[]} \\ {[]} & {[]} \\ {[]} & {[]}\end{array}$

(B) EXAMPLES OF CASE MIX QUESTIONS

Demographic information (from $P A S$ )

Patient audit number:

Sex: Male

[

[] Date of birth:

Female

[]

Postcode for

Stroke onset and hospital stay

1. Date of stroke:

2. Date of admission:

4. Date of death:

Functional status: pre-stroke and at discharge

5. Living accommodation:

Independent housing

Warden controlled

Residential / nursing home

Hospital

6. If living at home:

Lives alone

Lives with spouse/carer

usual address:

7. Dependency (using the Barthel ADL functional assessment scale) pre-stroke and at discharge (20 point version)

8. Previous stroke: Yes [] No []

Clinical status on admission

9. Worst level of consciousness in 24 hours following stroke:

Fully conscious

Drowsy (responds to speech)

Semi-conscious (not fully rousable)

Unconscious (responds to pain only/no response)

Dead

$\begin{array}{ll}{[} & ] \\ {[} & ] \\ {[} & ]\end{array}$

10. Side of body affected:
No clear lateralising signs

$\begin{array}{ll}\text { 10. } & \text { Side of body affected: } \\ \text { No clear lateralising signs }\end{array}$

Right side

Left side

Both
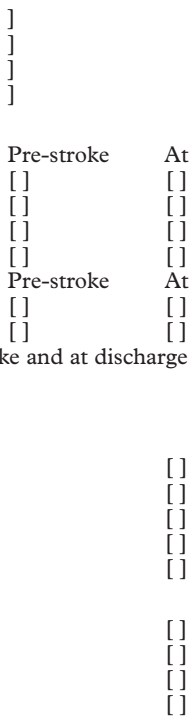

At seven days

11. Urinary continence at 1 week:

$0=$ incontinent $/$ catheterised

$1=$ occasional accident (max. once per 24 hours)

$2=$ continent (over previous 48 hours)

$3=$ patient died within 7 days

12. Clinical classification:

Cerebral infarction

Intracerebral haemorrhage

Subarachnoid haemorrhage

Other

Don't know

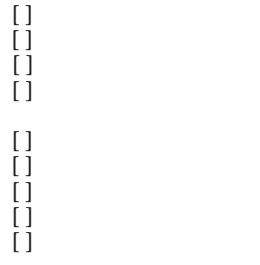




\title{
(C) EXAMPLES OF PROCESS AUDIT QUESTIONS
}

Physiotherapy assessment

2.2.1 Has the patient been assessed by a physiotherapist within 72 hours of admission?

Answer No, but... if patient died within 72 hours; patient is receiving palliative care.

Communication

2.3.1 Has there been an initial assessment of communication problems by the speech and language therapist within 7 days of stroke?

Answer No, but... if patient died within 7 days; the patient was still unconscious; it is documented that the patient had no communication problems; patient is receiving palliative care.

Ability to cope at home

2.3.2 Was the patient assessed by an occupational therapist within 7 days of admission?

Answer No, but... if patient died within 7 days; the patient was still unconscious; it is documented that the patient had no difficulties performing everyday activities; patient is receiving palliative care.

$\begin{array}{lll}\text { Yes } & \text { No } & \text { No, but ... } \\ \text { [] } & \text { [] } & \text { [] } \\ \text { [] } & \text { [] } & \text { [] } \\ & & \\ \text { [] } & \text { [] } & \text { [] }\end{array}$

\section{Leadership \& learning for better quality healthcare-just what does it take?}

\author{
Friday 2 November 2001
}

\section{Queen Elizabeth II Conference Centre, London SW1}

We are delighted to announce this forthcoming conference in London.

This conference will consider just what it takes in terms of leadership and learning to guarantee good quality care to users of health services.

Negative press concerning system failure in the NHS is widespread, and has been gaining momentum over the last 5 years. The NHS is poised to take a system wide initiative concerning leadership. This conference will explore what it will take in leadership and learning to make a real difference to the quality of health care. Leadership and learning will be explored at multiple-levels within the organisation, in educational programmes, and at the system level.

Presented to you by QHC, BMJ Publishing Group and The Nuffield Trust

Email: confunit@bma.org.uk or look at the website http://web3.bma.org.uk/confweb.nsf

Tel: +44 (0) 2073836605 Fax: +44 (0) 73736663

PGEA \& CME APPROVAL APPLIED FOR 